\title{
Review on Management of Hospital Waste in An Efficient Manner
}

\author{
Mathusuthan Kumarasamy ${ }^{1}$, Vasanthiny Jeevaratnam ${ }^{2}$
}

${ }^{1}$ Department of Community \&Family Medicine ,faculty of Medicine , University of Jaffna, Sri Lanka.

${ }^{2}$ Department of Agricultural Engineering, Faculty of agriculture, University of Jaffna, Sri Lanka.

\begin{abstract}
This is a review paper which is prepared from the surveys of hospitals and research studies. Hospital waste management in the world is a strict discipline and does occupy a serious place in the management of health care sector. The management of hospital remaining requires its removal and disposal from the health care establishments as hygienically and economically as possible by methods that all stages minimizes the risk to public health and to environment. Health care waste can be dangerous, if not done properly. Poor management of healthcare waste exposes health labors, waste handlers, and the community to the toxic effects of wastes generated from health activity. The disposal of these wastes could also lead to environmental problems. This article intends to describe various health care wastes and its controlling, as creating good practices for proper handling and disposal of health care waste is an important part of the health care delivery system. The aim of this paper is to highlight the present condition of medical waste and a review on scientific method of hospital waste management.
\end{abstract}

Keywords-Environmental problems, Hazardous waste, Hospital waste management, Medical waste, waste generation.

\section{INTRODUCTION}

Waste in general is any substance (solid, liquid, or gas) that has no direct use and is discarded permanently. A waste is considered hazardous if it exhibits any of the characteristics such as being flammable, reactive, explosive, corrosive, radioactive, infectious, irritating, sensitizing, or bio-accumulative[1]. Hospital waste refers to all waste generated, discarded and not intended for further use in the hospital. The risks are not only connected to the handling of the waste but also the environmental risk connected to the treatment and disposal of the waste. The proper management of biomedical waste has become a worldwide humanitarian topic today. Although hazards of poor management of biomedical waste have aroused the concern world over, especially in the light of its far-reaching effects on human, health and the environment[2].

Waste management options need to be efficient, safe and environment friendly to protect people from voluntary and accidental exposure to waste when collecting, handling, storing, transporting, treating or disposing of waste. Furthermore, in the Sri Lankan context such options need to be cost effective, taking into account the local logistical needs. Though clinical waste management should be an integral part of the health care delivery system the principal reason for absence of such infrastructure is economic. Health personnel are still to distinguish health care waste from ordinary garbage[3].

The objectives of biomedical waste management involve mainly prevention of disease transmission from one patient to another; to health workers from patients and vice versa; prevention of injury to the workers in health care units as well as workers involved in support services. This helps in turn in prevention of exposure to the deleterious effects of the cytotoxic as well as genotoxic and chemical wastes in general that are generated in the hospitals. Management of waste can be relatively effective as well as efficient practice that is related to compliance when designing is done properly[4]. World Health Organization states that $85 \%$ of hospital wastes are actually non-hazardous, whereas $10 \%$ are infectious and 5\% are noninfectious but they are included in hazardous wastes. About $15 \%$ to $35 \%$ of Hospital waste is regulated as infectious waste. This range is dependent on the total amount of waste generated[2].

As far as the management of biomedical wastes is concerned its proper management has become a humanitarian topic worldwide. Hazardous and poor waste management (biomedical) has become a matter of concern particularly in the light of its effects that are far reaching affecting human and animal health and the environment[4].

The World Health Organization (WHO) recognizes that in many countries improper management and disposal of clinical waste continue a significant threat to the healthy working environment. In general, clinical waste is reflecting high quantity, intensive disposal route and significantly higher costs compared to other waste categories. Thus, many hospitals have faced financial difficulties in managing of clinical waste. Equally in Sri Lanka, although the regulations had been gazetted by Central Environmental Authority (CEA) that improper disposal of clinical waste is an offense, still it remains as a 
problematic area[5]. Further, there are less special strategies have been established within the local level in order to manage clinical waste in cost effective manner.

According to the report identification of cost effective solutions for disposal of clinical waste is one of the main challenge face by hospitals since it require high technological and capital input. Though, few of the major hospitals operate modern treatments or outsource to a private sector, most hospitals are lacking of cost effective options to dispose clinical waste.

The objective of this paper is to introduce readers about the medical waste management, definition of medical wastes, risks of exposure, medical waste management procedures and control techniques.

\section{DEFinition OF Bio Medical WaSte}

According to Biomedical Waste (Management and Handling) Rules, 1998 of India "Any waste which is generated during the diagnosis, treatment or immunization of human beings or animals or in research activities pertaining thereto or in the production or testing of biological.

The Government of India (notification, 1998) specifies that Hospital Waste Management is a part of hospital hygiene and maintenance activities. This involves management of range of activities, which are mainly engineering functions, such as collection, transportation, operation or treatment of processing systems, and disposal of wastes[2].

\section{Classification OF Bio Medical Waste}

\subsection{Non-Hazardous Wastes}

In most of the set-ups of health-care approximately $85 \%$ of generated wastes are constituted by non-hazardous wastes. This includes wastes constituting remnants of food and peels of fruit; wash water as well as paper cartons; packaging materials[6].

\subsection{Hazardous Wastes}

Potentially Infectious Wastes In the scientific documents as well as in the regulations and guidance various terms for infectious wastes have been used over the years. These include, infectious as well as infective medical and biomedical; hazardous and red bag, contaminated, infectious medical wastes along with regulated wastes in the medical profession. Basically all these terms indicate the similar types of wastes even though the terms involved in regulation are defined usually in more Specific manner[7].

\section{Problems Relating to Biomedical Waste}

A key issue related to current biomedical waste management in many hospitals is that the application of Bio-Waste regulation is poor as some hospitals are disposing of waste in a random, improper and uncritical manner. Lack of segregation practices, results in mixing of hospital wastes with general waste making the whole waste stream hazardous. Inappropriate segregation ultimately results in an incorrect method of waste disposal.

Insufficient Bio-Medical waste management thus will cause environmental pollution, unpleasant smell, growth and multiplication of vectors like insects, rodents and worms and may lead to the transmission of diseases like typhoid, cholera, hepatitis and AIDS through injuries from syringes and needles contaminated with human. Various communicable diseases, which spread through water, sweat, blood, body fluids and contaminated organs, are important to be prevented.

The Bio Medical Waste scattered in and around the hospitals invites flies, insects, rodents, cats and dogs that are responsible for the spread of communication disease like plague and rabies. Rag pickers in the hospital, sorting out the garbage are at a risk of getting tetanus and HIV infections. The recycling of disposable syringes, needles, IV sets and other article like glass bottles without proper sterilization are responsible for Hepatitis, HIV, and other viral diseases. It becomes primary responsibility of Health administrators to manage hospital waste in most safe and eco-friendly manner.

Although treatment and disposal of health-care wastes aim at reducing risks, indirect health risks may occur through the release of toxic pollutants into the environment through treatment or disposal.

a) Landfilling can lead to contamination of drinking water

b) Occupational risks may be associated with the operation of certain disposal facilities. 
c) Inadequate incineration or incineration of materials unsuitable for incineration can result in the release of pollutants into the air. The incineration of materials containing chlorine can generate dioxins and furans, which are potential carcinogens.

d) Incineration of heavy metals or materials with high metal contents (lead, mercury and cadmium) can lead to the spread of heavy metals in the environment. Dioxins, furans and metals are persistent and accumulate in the environment. Only modern incinerators which are able to work at $800-1000^{\circ} \mathrm{C}$ with special emission cleaning equipment can ensure that no dioxins and furans (or only insignificant amounts) are produced.

\section{APPROACH FOR HOSPITALWASTE MANAGEMENT \\ TABLE 1 \\ HOSPITAL WASTE CATEGORIES AND DISPOSAL}

\begin{tabular}{|c|c|}
\hline Waste Category & Treatment \& Disposal \\
\hline Human anatomical waste & Incineration /deep burial \\
\hline Animal waste & Incineration /deep burial \\
\hline Microbiology \& biotechnology waste & Incineration / disinfection /chemical treatment /mutilation \\
\hline Sharps & Incineration / destruction and disposal in secured landfill \\
\hline Medicines and cytotoxic drugs & Autoclave/chemical treatment/burial \\
\hline Solid waste (Blood and Body fluids) & Autoclave/chemical treatment/burial \\
\hline Solid waste (disposable items) & Disinfection by chemicals/discharge into drains \\
\hline Liquid waste ( blood \& body fluids) & Disposal in municipal landfill \\
\hline Incineration Ash & Chemical treatment/ secure landfill \\
\hline Chemical waste &
\end{tabular}

\section{Hospital Waste Management Programme}

1. Identification of waste types

2. Segregation of waste

3. Transport \& storage of waste

4. Proper disposal of waste

5. Implementation of contingency plans

6. Identify the need for use of personal protective equipment

\subsection{Segregation by color coding system}

- Infectious waste - Red bags

- Domestic waste - Green Bags

- Sharps - Needle cutters / Puncture proof containers

- Segregation at Source ( ward, operation theater, laboratory, labour room, other places)

\subsection{Transportation}

- Containers: puncture proof, leak proof,

- Bags: sturdy, properly tied

- Transport trolleys: designated \& timely

- Staff protection: provided with protective clothing and other items

- Never put hands in a bag

\subsection{Waste storage}

- Closed covered area

- Away from the normal passages 
- Easily accessible for transportation

- Radioactive waste special containers/ special treatment and disposal

\subsection{Proper disposal of waste}

- All infectious waste and sharps containers :Incineration

- All Domestic waste : Landfill

- All hazardous waste : Chemical treatment before disposal

- Implementation of contingency plans

- Contingency plans have to be in place to be implemented whenever any of the steps in the chain breaks and everyone should be aware of their responsibilities in case of breakdown.

\subsection{Identify the need for use of personal protective equipment}

- Special clothing, gloves, masks and eye protection should be identified and provided to the healthcare workers responsible for waste transportation and disposal.

\subsection{On-Site Medical Waste Treatment}

\subsubsection{Autoclaving}

Thermal treatment is typically used for sharps and certain other types of infectious waste. An autoclave is in essence a large pressure cooker that uses high temperatures and steam to deeply penetrate all materials and kill any microorganisms. Depending on the type and amount of waste you will need to sterilize, you can purchase an appropriately-sized autoclave for your facility. These appliances range from 100 liters to 4,000+ liters in volume for bulk waste treatment[8].

Modern autoclaves are also automated to minimize human involvement and therefore reduce needle-stick injuries and contamination. Decontaminated sharps and other medical waste that's been autoclaved can then be handed over to your Maryland medical waste removal vendor to be disposed of as non-infectious waste. However, keep in mind that such medical wastes as chemical waste, including chemotherapy waste, as well as pharmaceutical waste can't be decontaminated in an autoclave.

\subsubsection{Chemical Treatment}

Often used to deactivate liquid waste, chemical treatment is designed to decontaminate or deactivate certain wastes on site rather than packaging and sending them to a separate facility. Since liquids are highly susceptible to spills, it's typically best to have them treated as close to the generation site as possible. Chemical treatment can also be applied to some non-liquid infectious wastes, but they would typically need to be shredded first to ensure that all portions of the waste are exposed to the chemicals.

Depending on the type of waste, chemicals like chlorine, sodium hydroxide or calcium oxide can be used.

\subsubsection{Microwave Treatment}

A microwave treatment system, similar to an autoclave, also uses heat to decontaminate medical waste. These systems work best for waste that is not $100 \%$ dry or solid, as the moisture allows the heat to penetrate deeper, and the steam sterilizes. Therefore, before microwaving, most types of medical waste need to be shredded and mixed with water to achieve the desired effect. The bonus is that shredding reduces the volume of the waste, so it can later be land-filled.

\subsection{Off-Site Medical Waste Disposal}

\subsubsection{Incineration}

Incineration is typically used (and often required by the state) for pathological and pharmaceutical waste. Incineration of medical waste should be performed in a controlled facility to ensure complete combustion and minimize any negative effects for the environment[9]. The great thing about incineration is that it kills $99 \%$ of microorganisms and leaves very minimal waste, if any. 


\subsubsection{Land Disposal}

Land disposal is typically used for shredded, treated and decontaminated waste. In certain cases, it can also be used for hazardous waste or other untreated waste that cannot be decontaminated by other means. Specialized sanitary landfill sites exit to reduce the risk of soil and water contamination and provide a safe space for medical waste disposal.

\subsubsection{Plasma Pyrolysis}

Direct use of waste products as combustion fuel or their indirect processing into another kind of fuel helps in harnessing the energy contents. In this context pyrolysis has been found as a related form of thermal treatment wherein high temperatures are used for treating waste materials with limited supply of oxygen. A state-of-the-art is plasma pyrolysis technology that ensures disposal safe of medical wastes[10].

\section{CONCLUSION}

Medical wastes should be classified according to their source, typology and risk factors associated with their handling, storage and ultimate disposal. The segregation of waste at source is the key step and reduction, reuse and recycling should be considered in proper perspectives. For proper management of biomedical wastes lack of concern and awareness as well as cost factors are the certain problems/limitations. Therefore general public should be educated and must be concerned regarding health hazards that are associated with biomedical wastes. Ultimately, sensitizing ourselves is of utmost importance for protection of environment and our own health. In this paper, introductory materials on the definition of medical waste, medical waste management regulatory acts, the risks of exposure, medical waste management procedures and control techniques are presented.

\section{REFERENCES}

[1] Shareefdeen, Z.M., Medical waste management and control. Journal of Environmental Protection, 2012. 3(12): p. 1265.

[2] Mathur, P., S. Patan, and A.S. Shobhawat, Need of biomedical waste management system in hospitals-An emerging issue-A review. Current World Environment, 2012. 7(1): p. 117-124.

[3] Haniffa, R., Management of health care waste in Sri Lanka. Ceylon Medical Journal, 2011. 49(3).

[4] Chakraborty, S., et al., Biomedical Waste Management. Interaction, 2013. 2013: p. 12-02.

[5] Karunasena, G. and W.J.a.R. Rathnayake, Comparison on Disposal Strategies for Clinical Waste: Hospitals In Sri Lanka. 2016.

[6] Hegde, V., R. Kulkarni, and G. Ajantha, Biomedical waste management. Journal of Oral and Maxillofacial Pathology, 2007. 11(1): p. 5.

[7] Block, S.S., Disinfection, sterilization, and preservation. 2001: Lippincott Williams \& Wilkins.

[8] Rutberg, P.G., et al., The technology and execution of plasmachemical disinfection of hazardous medical waste. IEEE transactions on plasma science, 2002. 30(4): p. 1445-1448.

[9] Thornton, J., et al., Hospitals and plastics. Dioxin prevention and medical waste incinerators. Public Health Reports, 1996. 111(4): p. 298.

[10] Katoch, S.S. Biomedical waste classification and prevailing management strategies. in Proceedings of the International Conference on Sustainable Solid Waste Management. 2007. 